\title{
THE IMPACT OF DENSITY AND MIXTURE RATIO OF MELAMINE ON SOME PROPERTIES OF ORIENTED STRAND BOARD
}

\author{
Mehmet Hakan Akyildiz ${ }^{1}$, Kadir Dogan ${ }^{2, \star}$, Alperen Kaymakci $^{1}$
}

In memoriam of Dr. Thomas C. MANNES

\begin{abstract}
The aim of this study is to determine the effects of density and melamine rate on thickness swelling, moisture resistance, modulus of elasticity in bending, bending strength and tensile strength of Oriented Strand Board. For this purpose, Oriented Strand Board panels were produced at three different density $\left(550-570-590 \mathrm{~kg} \cdot \mathrm{m}^{-3}\right.$ in size of $\left.2440 \times 1220 \times 11 \mathrm{~mm}\right)$ and at five different mixture ratio of melamine in urea formaldehyde resin $(0 \%-2,5 \%-5 \%-15 \%-20 \%)$. Urea formaldehyde and melamine urea formaldehyde included $65 \%$ solid content was used of $9,5 \%$ ratio relatively dry wood chip weight. At the process of Oriented Strand Board panels, Black pine (Pinus nigra), Scots pine (Pinus sylvestris) and Fir wood (Abies nordmanniana) chips were used at a rate of $80 \%, 15 \%$, and 5\%, respectively.

Obtained results show that a linear correlation between the value of horizontal bending resistance, modulus of elasticity with panel density and melamine amount. It was understood that the values of longitudinal bending resistance did not show a direct increasing or decreasing in melamine amount and value of density. As it is seen that the values of longitudinal modulus of elasticity increases in proportion with the increase in the density. In perpendicular tensile strength to the surface; it is seen that values of all glue groups and density values which are intended by the standard for density values are covered. As melamine reinforcement ratio increases, average values of free formaldehyde decrease. It was determined that there was no direct correlation between the value of thickness swelling and panel density, and it had a correlation with used glue type.
\end{abstract}

Keywords: Mechanical properties, melamine ratio, melamine urea formaldehyde resin, modulus of elasticity, physical properties.

\section{INTRODUCTION}

Oriented Strand Board (OSB) is a material in the form of a board that is produced by pressing the draft obtained within the strands which are specially prepared and then mixed with suitable glue and oriented in the desired direction under temperature and pressure during laying (Akbulut et al. 2002). The most important difference of OSB from known strand boards is larger and specially shaped strands (generally $15-25 \mathrm{~mm}$ in width, $75-150 \mathrm{~mm}$ in length $0,3-0,7 \mathrm{~mm}$ in thickness) to be used in process, to be mixed with different glue and protective chemicals in a different boiler, and then pressed and laid in a direction oriented to certain directions (Irle and Barbu 2010).

According to the classification made by Bozkurt and Goker (1990), oriented strand boards are included in the group of medium- density strand boards. While urea formaldehyde (UF) glue is used in the strand board industry in general; phenol formaldehyde (PF), melamine urea formaldehyde (MUF), melamine urea phenol formaldehyde (MUPF) or methylene diisocyanate (MDI) glues are used in the OSB industry (Irle and Barbu 2010, Mendes et al. 2013). 
While approximately $75 \%$ of the OSB is used for constructions, $20 \%$ of it is used for packaging and the remaining is used for other decorative purposes (Irle and Barbu 2010). At present, with the rapid development of engineering and technology, the number of wood-based materials is increasing, and the possibilities for their application are being extended. OSB is a state-of-theart material especially suitable for use in building industry as construction material for walls, roofs and floors, as well as for the manufacture of the so-called "I" beams. OSB is a material manufactured from flat wood chips arranged in layers (usually 3 layers), which are oriented perpendicular to each other and connected under pressure with some water-resistant adhesive (Böhm et al. 2011).

It was reported that wood species, specific mass, strand geometry, type of glue, amount of glue, pressing conditions and draft structure affect the physical and mechanical properties of the strand board, and all other properties except thickness swelling and dimensional stability improved by increasing of specific mass (Akbulut 1999, Candan et al. 2017, Mendes et al. 2013). According to Goker and Akbulut (1992), Phenolic glues and isocyanate glues should be used for strand boards to be used in places exposed to outdoor weather conditions and urea formaldehyde glues should be used for general purpose strand boards to be used in bowels and indoors. All resistance properties and dimensional stability of the board improve by increasing the amount of glue used. Akbulut (1999) stated that the perpendicular tensile strength to the surface was directly related to the amount of glue applied to the unit strand surface and that the increase in the amount of glue significantly increased the perpendicular tensile strength to the surface. It has been stated that high formaldehyde rate glue could be used to increase the mechanical resistances in chipboards and the specific gravity of board could be increased (Nemli 2002, Nemli 2003). Young and Kim (2007) found that melamine urea formaldehyde glue gave better mechanical values, better water resistance and lower free formaldehyde value than urea formaldehyde glue in chip board.

Avramidis and Smith (1989) reported that the increase in surface and middle layer proportions and the amount of glue improved the physical and mechanical properties of OSB samples. Zhou (1989) found that as the board density increased in fast growing hybrid poplar wood, mechanical properties improves, and as it thickened, swelling and water absorption value increased. In addition, he reported that the improvement of the bending resistance and the value of modulus of elasticity in the direction parallel to the longitudinal direction of the board by improving chip orientation. Suziki and Takeda (1999) found that in Japanese Sugi (Cryptomoria japonica) wood, the mechanical properties in OSB were influenced by the chip size and layer structure and there was no significant difference in tensile strength.

Akbulut et al. (2002) reported that even though the resistance values of OSB plates were lower than plywood boards, they could be used in areas such as packaging board, flooring, under floor, roofing, and wall partitioning instead of structural plywood. Brochmann et al. (2004) reported that the chip thickness in the middle and the surface layer and the glue type used in the middle and the surface layer were separately effective for the tensile strength according to the results of the mechanical properties in the OSB, and glue type was effective for the high tensile value of the board. Phenol glue had a strong effect especially on the surfaces, while the highest tensile value was obtained when thicker chips are used throughout the panel. The tensile value in the boards having much more density increased.

Jaroslav and Pavel (2009) investigated the effect of changes in glue quantity and density on the mechanical properties of OSB plates and found that lowering board density reduced bending resistance and value of modulus of elasticity.

Saldanha and Iwakiri (2009: 571) obtained better results in bending resistance (MOR), modulus of elasticity (MOE), tensile and water absorption values by increasing board density in boards produced with different glues in Pinus taeda wood. Plates produced with phenol formaldehyde gave better results in all of the properties, except for the perpendicular bending and elasticity modulus. Febrianto et al. (2010) found that the OSBs produced with high-density wood had lower values of bending strength and modulus of elasticity. When these types of wood chips were mixed with lower density wood chips, the value of the bending resistance and modulus of elasticity were increased. Barbuta et al. (2012) reported that board density was a critical parameter positively affecting the mechanical properties of OSB plates. 
Gunduz et al. (2011) found that perpendicular pulling (IB), bending resistance (MOR) and modulus of elasticity (MOE) values increased as the pressing time and glue ratio increase in the chips produced with $80 \mathrm{~mm}$ chips of Scots pine wood with phenol formaldehyde glues at different ratios. Esen et al. (2013) found that the modulus of elasticity of the OSB plates produced with the $80 \mathrm{~mm}$ long chips obtained from the Scots pine did not have a significant effect of the pressing time and pressing pressure; they only had the positive effect on the screw withdrawal strength. Esen et al. (2013) found that there were effects of glue type, glue ratio, pressing time and pressing pressure on the modulus of elasticity and the bending resistance in OSB plates produced with phenol formaldehyde from the Scots pine wood.

Bufalino et al. (2015) investigated feasibility of using and mixing Toona ciliata, Eucalyptus grandis/ urophylla and Pinus oocarpa woods in OSB production Three one-species and four mixed-species combinations were compared. Phenol-formaldehyde (PF) adhesive was applied at $9 \%$ for all OSB panels. Three-layer mats with mass proportion of $25 / 50 / 25 \%$ for surface/core/surface were produced. The results obtained show that Eucalyptus wood has great potential to substitute Pinus wood in OSB production. The utilization of T. ciliata wood for OSB production decreased mechanical performance, but remarkably enhanced water resistance properties.

The purpose of this study is to determine the effect of density and melamine reinforcement ratio on the physical and mechanical properties of OSB plates after producing the boards at different densities by adding melamine to the urea formaldehyde glue used in the process of OSB at different densities. As a result, the process conditions that give the standard values of OSB plates will be determined, the process of boards will be done with a kind of glue that can be supplied cheaper and easily, and therefore this contributes an economically profitable process.

\section{MATERIALS AND METHODS}

In this study, Black pine (Pinus nigra A.), Scots pine (Pinus silvestris L.) and fir (Abies nordmanniana L.) woods were used for the process of OSB. Diameters of the woods were between 10 and $30 \mathrm{~cm}$, their lengths were $2 \mathrm{~m}$, and after the barks were peeled off in two rotatory drumsticks in drum debarker, flakes were obtained in the ring flaker with thicknesses of $0,5-1,0 \mathrm{~mm}$, widths of 15 - $25 \mathrm{~mm}$ and lengths of $65-85 \mathrm{~mm}$. The mixture consisting of $80 \%$ of Black pine, $15 \%$ of Scots pine and $5 \%$ of fir flakes were used in the process of boards.

The amount of melamine-urea-formaldehyde (MUF) solid glue with $65 \%$ urea formaldehyde (UF) affixed with $2,5 \%-5 \%-15 \%$ and $20 \%$ melamine content in the process of boards was $9,5 \%$ of the dry chip, Ammonium sulphate was used at a rate of $2,2 \%$ of glue solids for the surface layer and $2,6 \%$ of glue solids for the middle layer. In order to increase the resistance of board to moisture and water, paraffin at $40 \%$ concentration was used as water-repellent chemical substance, which is $0,6 \%$ in proportion to dry flake. The values of glue and chemicals used in the study are given in Table 1. 
Table 1. The characteristics of glue and chemicals used in the process.

\begin{tabular}{|l|c|c|c|c|c|c|c|}
\hline \multirow{2}{*}{ Adhesive/Chemical } & Solid content & Density & Viscosity & & Mole ratio & Flow time & Gel time \\
\cline { 2 - 8 } & $(\%)$ & $\left(\mathrm{g} \cdot \mathrm{cm}^{-3}\right)$ & $(\mathrm{cP})$ & $\mathrm{pH}$ & $(\mathrm{MR})$ & $(\mathrm{sec})$ & $(\mathrm{sec})$ \\
\hline UF (M:\%0) & 65 & 1,3 & 430 & 8,2 & 1,30 & 75 & 43 \\
\hline MUF (M:\%2,5) & 65 & 1,290 & 420 & 8,6 & 1,13 & 82 & 59 \\
\hline MUF (M:\%5,0) & 65 & 1,287 & 493 & 8,5 & 1,13 & 105 & 50 \\
\hline MUF (M:\%15) & 65 & 1,290 & 484 & 9,0 & 1,23 & 84 & 65 \\
\hline MUF (M:\%20) & 65 & 1,305 & 253 & 9,2 & 1,13 & 50 & 80 \\
\hline Paraffin & 40 & 0,93 & 46 & 8,0 & - & 12 & - \\
\hline Ammonium sulphate & 10 & 1,10 & 7,0 & 8,2 & - & - & - \\
\hline
\end{tabular}

The test plates were produced in three different board densities with the same glues having different melamine content under the same process conditions. Process conditions of boards are given in Table 2 .

Table 2. Process conditions of test boards.

\begin{tabular}{|c|c|c|c|c|c|c|}
\hline \multirow{2}{*}{ Process Conditions } & \multirow{2}{*}{ Board density } & \multicolumn{5}{|c|}{ Melamine addition rate } \\
\hline & & 0 & 2,5 & 5 & 15 & 20 \\
\hline & $\left(\right.$ kg. $\left.\mathrm{m}^{-3}\right)$ & \multicolumn{5}{|c|}{$(\%)$} \\
\hline Pressing Temperature $\left(\mathrm{C}^{\circ}\right)$ & \multirow{4}{*}{$\begin{array}{l}550 \\
570\end{array}$} & \multicolumn{5}{|c|}{180} \\
\hline Pressing Time (s) & & \multicolumn{5}{|c|}{200} \\
\hline Pressing Factor $\left(\mathrm{s} . \mathrm{mm}^{-1}\right)$ & & \multicolumn{5}{|c|}{11,5} \\
\hline Solid glue / Solid chip (\%) & & \multicolumn{5}{|c|}{9,6} \\
\hline
\end{tabular}

The flakes were dried in a three-pass rotary drum dryer with drying output moisture of 3-5\%. Dried flake glue and chemicals were sprayed in the rotating drum type glue mixer (blender) with atomizers and in the order of the paraffin, glue, and hardener.

The glued flakes were laid with two disk head guides for the surface layers one at the beginning of the laying line and the other at the end, and firstly the lower surface of the board was formed and then the upper surface was formed after the formation of the middle layer. The flakes for the formation of the middle layer were laid vertically to the production direction with a paddling guide partaking in forming head.

The flake mat formed on forming line was pressed with a heating factor of $11,5 \mathrm{~s} . \mathrm{mm}^{-1}$ under a temperature of $180^{\circ} \mathrm{C}$ in a six-layer simultaneous press to form plates with a thickness of $11,0 \pm 0,8$ $\mathrm{mm}$ and a size of $1220 \times 2440 \mathrm{~mm}$. 5 of the boards produced were taken as test boards. Test samples for process conditions (Table 2) were cut from these boards.

From the prepared samples, firstly the free formaldehyde test samples were conditioned to a constant mass of under the conditions of $45 \pm 5 \%$ relative moisture and $23 \pm 1{ }^{\circ} \mathrm{C}$ temperature. For other experiments, tests were carried out according to the Turkish Standards after being kept until constant weight at $65 \pm 5 \%$ relative moisture and $20 \pm 2{ }^{\circ} \mathrm{C}$ temperatures in the air-conditioning cabinet.

In order to determine properties of produced boards; density measurements were made according to standard determination of density TS EN 323, bending resistance and modulus of elasticity in bending of bending strength TS EN 310, determination of tensile strength perpendicular to the plane of the board TS EN 319, determination of swelling in thickness after immersion in water TS EN 317, determination of moisture content TS EN 322, determination of moisture resistance TS EN 1087-1 and determination of formaldehyde content- Extraction method called the perforator method (Separation by Extraction Method) TS 4894 EN 120.

\section{Evaluation of Data}

In this study, Analysis of Variance was used in order to determine the effects of different board densities $\left(550 \mathrm{~kg} \cdot \mathrm{m}^{-3}, 570 \mathrm{~kg} \cdot \mathrm{m}^{-3}\right.$ and $\left.590 \mathrm{~kg} \cdot \mathrm{m}^{-3}\right)$ and melamine ratios $(\% 0-2,5-5-15-20)$ added into UF glue on bending resistance of board, modulus of elasticity, perpendicular tensile strength to surface and values of thickness swelling for 24 hours and Duncan Test was used for paired comparisons. 
Sample number (n), arithmetic average $(\bar{x})$ and standard deviation (S) values were calculated and they were given in tables for each test.

\section{RESULTS AND DISCUSSION}

\section{Board Moisture Value}

Average results of board moisture value of pressing output after production for each glue and density groups were given in Table 3 .

Table 3. Average board moisture values after pressing.

\begin{tabular}{|cccccc|}
\hline \multirow{2}{*}{ Board density } & \multicolumn{5}{c|}{ Glue mixture ratios } \\
\cline { 2 - 6 } & $\begin{array}{c}\text { UF } \\
(\text { M: 0\%) }\end{array}$ & $\begin{array}{c}\text { MUF } \\
(\text { M: 2,5\%) }\end{array}$ & $\begin{array}{c}\text { MUF } \\
(\text { M: 5.\%) }\end{array}$ & $\begin{array}{c}\text { MUF } \\
(\text { M: 15\%) }\end{array}$ & $\begin{array}{c}\text { MUF } \\
(\text { M: 20\%) }\end{array}$ \\
\hline 550 kg.m ${ }^{-3}$ & 3,8 & 3,9 & 3,5 & 3,6 & 3,9 \\
570 kg.m ${ }^{-3}$ & 5,0 & 4,5 & 4,3 & 4,7 & 4,0 \\
590 kg.m ${ }^{-3}$ & 4,0 & 4,1 & 3,7 & 4,7 & 4,1 \\
\hline
\end{tabular}

Board moisture value might be change according to wet flake moisture, drying output moisture, glued flake moisture arising from chemical amounts and glue given in glue blender, pressing temperature and time and ambient temperature and change in moisture.

\section{Bending Resistance and Modulus of Elasticity}

Bending resistance was determined according to laying style of flakes in the direction parallel (longitudinal) to process direction and perpendicular (horizontal) to process direction, and value of modulus of elasticity was determined according to each of density group and glue type. Statistical evaluations of resistance values were made and the results were interpreted.

Horizontal Bending Resistance of Board and Modulus of Elasticity

According to the result of bending test made in the direction perpendicular (horizontal) to process direction, changes of resistance values obtained according to different melamine contents (M\%) for every density value were given in Figure 1.

According to statistical results, values of horizontal bending resistance showed significant differences according to panel density and melamine ratio in the glue $(p<0,05)$. The results of Duncan test which was made in order to determine the effects of panel density and melamine addition percentages were given in Table 4. 


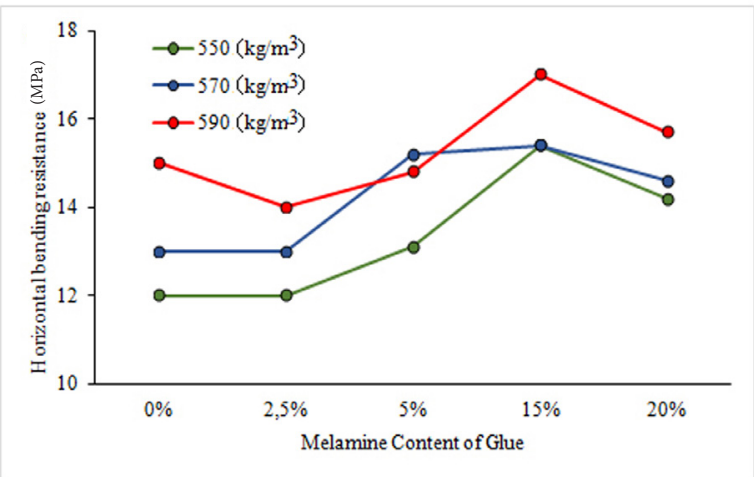

Figure 1. Change in horizontal bending resistance according to different panel density and melamine content.

According to Table 4, there were significant differences among every three density values in terms of horizontal bending resistance, and while lowest value of horizontal bending resistance was obtained at the density of $550 \mathrm{~kg} \cdot \mathrm{m}^{-3}$, the highest value of horizontal bending value was obtained at the density of $590 \mathrm{~kg} \cdot \mathrm{m}^{-3}$.

Table 4. The results of Duncan test on density and melamine content for horizontal bending resistance.

\begin{tabular}{|c|c|c|c|c|}
\hline \multirow{2}{*}{$\begin{array}{c}\text { Density } \\
\left(\mathrm{kg} . \mathrm{m}^{-3}\right)\end{array}$} & $\begin{array}{c}\text { Horizontal Bending Resistance } \\
(\mathrm{MPa})\end{array}$ & \multicolumn{3}{|c|}{ Homogeneous Groups } \\
\hline & 13,4 & 1 & 2 & 3 \\
\hline 550 & 14,3 & $*$ & & \\
\hline 570 & 15,2 & & & \\
\hline 590 & & & & $*$ \\
\hline $\begin{array}{c}\text { Melamine Ratio } \\
(\%)\end{array}$ & 12,9 & & & \\
\hline 2,5 & 13,3 & $*$ & & \\
\hline 0 & 14,4 & $*$ & & \\
\hline 5 & 14,9 & & $*$ & \\
\hline 20 & 16,0 & & $*$ & \\
\hline 15 & & & & $*$ \\
\hline
\end{tabular}

Thereby, as density increased horizontal bending resistance increased. According to the results of Duncan Test (Table 4) on melamine content in the glue, while there were panels produced with glues having melamine ratio of $0 \%$ and $2,5 \%$ in the group having lowest value of horizontal bending resistance, there was OSB group having melamine ratio of $15 \%$ in the group having the highest value of horizontal bending resistance.

Changes in values of modulus of elasticity obtained according to different density value in the perpendicular to panel process direction and different melamine content $(\% \mathrm{M})$ values were given in Figure 2. 


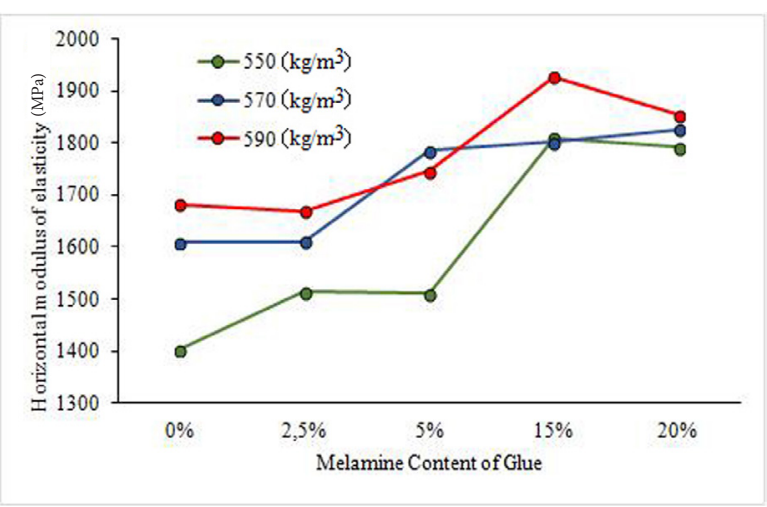

Figure 2. Changes in horizontal modulus of elasticity according to different panel density and melamine content.

According to statistical results, values of horizontal modulus of elasticity showed significant differences according to panel densities and melamine ratios in the glue $(p<0,05)$. The results of Duncan Test made in order to determine the effects of panel density and melamine addition percentages were given in Table 5 .

Table 5. The results of Duncan test on density and melamine content for the value of horizontal modulus of elasticity.

\begin{tabular}{|c|c|c|c|c|}
\hline \multirow{2}{*}{$\begin{array}{c}\text { Density } \\
\left(\mathrm{kg} . \mathrm{m}^{-3}\right)\end{array}$} & \begin{tabular}{c} 
Horizontal $\begin{array}{c}\text { Modulus of Elasticity } \\
(\mathrm{MPa})\end{array}$ \\
\cline { 3 - 4 }
\end{tabular} & \multicolumn{3}{|c|}{ Homogeneous Groups } \\
\hline 550 & 1606 & $*$ & & \\
570 & 1726 & & $*$ & \\
590 & 1776 & & & \\
\hline $\begin{array}{c}\text { Melamine Ratio } \\
(\%)\end{array}$ & 1565 & $*$ & & \\
\hline 0 & 1598 & $*$ & & \\
2,5 & 1680 & & $*$ & $*$ \\
5 & 1824 & & & $*$ \\
20 & 1847 & & & \\
\hline
\end{tabular}

According to the results of Duncan Test on panel density (Table 5), the lowest value of horizontal modulus of elasticity was obtained at the density of $550 \mathrm{~kg} \cdot \mathrm{m}^{-3}$. The highest value of horizontal modulus of elasticity was obtained at the density of $590 \mathrm{~kg} \cdot \mathrm{m}^{-3}$, as well as panels having density values of 570 kg. $\mathrm{m}^{-3}$ and $590 \mathrm{~kg} . \mathrm{m}^{-3}$ was in the same group, and statistically, there was no difference between them. However, the value of modulus of elasticity increased with the increase in density.

While the glues having melamine ratios of $0 \%$ and $2,5 \%$ had the lowest value of horizontal modulus of elasticity according to melamine ratios in the glue, they took place in the same group. While the glue reinforced with $15 \%$ of melamine gave the highest value of horizontal modulus of elasticity, it took place in the same homogenous group with the glue reinforced with $20 \%$ of melamine. The increase in melamine reinforcement ratio increased the horizontal modulus of elasticity. 


\section{Resistance values of bending longitudinal to panel}

Changes in resistance values obtained according to different density and different melamine content $(\mathrm{M} \%)$ in parallel to the process direction of the panel were given in Figure 3.

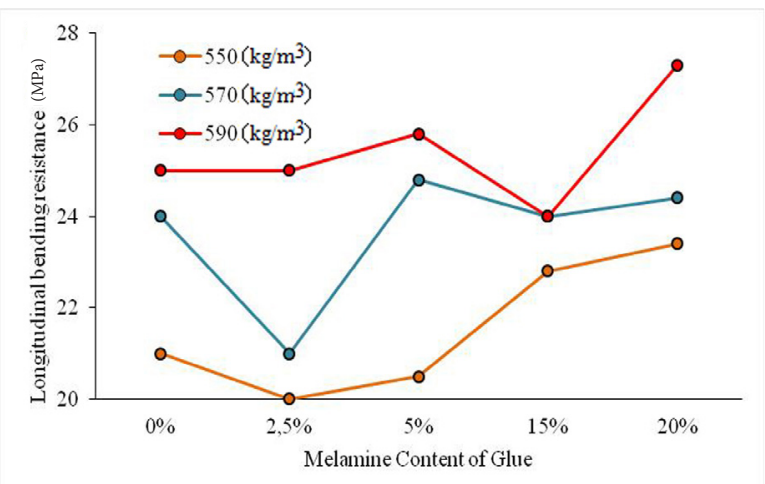

Figure 3. Change in longitudinal bending resistance according to different density and melamine content.

According to statistical results, values of longitudinal bending resistance showed significant differences according to panel densities and melamine ratios in the glue $(p<0,05)$. The results of Duncan Test made in order to determine the effects of panel density and melamine addition percentages were given in Table 6.

According to the results of Duncan test on panel density (Table 6), there were significant differences among every three density values in terms of value of longitudinal bending resistance and while the lowest value of longitudinal bending resistance was obtained at the density of $550 \mathrm{~kg} \cdot \mathrm{m}^{-3}$, the highest value of longitudinal bending resistance was obtained at the density of $590 \mathrm{~kg} . \mathrm{m}^{-3}$. Longitudinal bending resistance showed similarities with perpendicular bending resistance. However, values of longitudinal bending resistance were found higher.

Table 6. The results of Duncan test on density and melamine content for longitudinal bending resistance.

\begin{tabular}{|ccccc|}
\hline \multirow{2}{*}{$\begin{array}{c}\text { Density } \\
\left(\mathrm{kg} \cdot \mathrm{m}^{-3}\right)\end{array}$} & \begin{tabular}{c} 
Longitudinal $\begin{array}{c}\text { Bending Resistance } \\
(\mathrm{MPa})\end{array}$ \\
\cline { 3 - 5 }
\end{tabular} & \multicolumn{3}{c|}{ Homogenous Groups } \\
\hline 550 & 21,6 & $*$ & & \\
\hline 570 & 23,7 & & $*$ & \\
\hline 590 & 25,4 & & \\
\hline $\begin{array}{c}\text { Melamine Ratio } \\
(\%)\end{array}$ & & & \\
\hline 2,5 & 21,9 & $*$ & \\
\hline 0 & 23,3 & $*$ & $*$ \\
\hline 5 & 23,7 & $*$ & $*$ \\
\hline 15 & 23,8 & $*$ & $*$ \\
\hline 20 & 25,1 & & $*$ \\
\hline
\end{tabular}

According to the results of Duncan test on melamine ratios in the glue, the lowest longitudinal bending resistance was in the glue reinforced with $2,5 \%$ of melamine, and it took place in the same group with glues reinforced with $0 \%, 5 \%$ and $15 \%$ of melamine. The highest value of longitudinal 
bending resistance was obtained with the glue reinforced with $20 \%$ of melamine and it took place with the glues reinforced with $0 \%, 5 \%$ and $15 \%$ of melamine. Thereby, values of longitudinal bending resistance showed close values in terms of melamine reinforcement ratios.

Changes in values of modulus of elasticity obtained according to different density value in the longitudinal to panel process direction and different melamine content $(\% \mathrm{M})$ values were given in Figure 4.

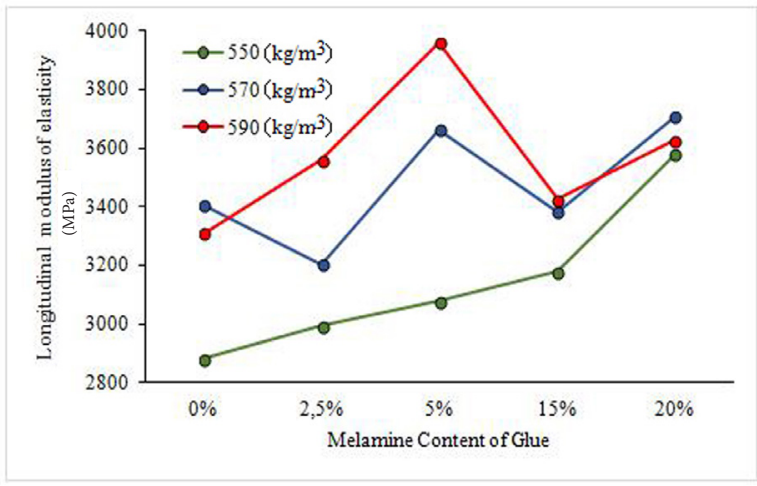

Figure 4. Changes in longitudinal modulus of elasticity according to different density and melamine content.

According to statistical results, the values of longitudinal modulus of elasticity showed significant differences according to panel densities and melamine ratios in the glue $(\mathrm{p}<0,05)$. The results of Duncan Test made in order to determine the effects of panel density and melamine addition percentages were given in Table 7.

Table 7. The results of Duncan test on density and melamine content for the value of longitudinal modulus of elasticity.

\begin{tabular}{|cccc|}
\hline \multirow{2}{*}{$\begin{array}{c}\text { Density } \\
\left(\mathrm{kg} . \mathrm{m}^{-3}\right)\end{array}$} & $\begin{array}{c}\text { Longitudinal Modulus of Elasticity } \\
(\mathrm{MPa})\end{array}$ & \multicolumn{2}{c|}{ Homogeneous Groups } \\
\hline 550 & 3144 & $*$ & 2 \\
\hline 570 & 3471 & & $*$ \\
\hline 590 & 3576 & & \\
\hline $\begin{array}{c}\text { Melamine Ratio } \\
(\%)\end{array}$ & & $*$ & \\
\hline 0 & 3198 & $*$ & $*$ \\
\hline 2,5 & 3253 & $*$ & $*$ \\
\hline 15 & 3329 & & \\
\hline 5 & 3567 & & $*$ \\
\hline 20 & 3637 & & \\
\hline
\end{tabular}

According to the results of Duncan test on panel density and melamine content (Table 7), two groups were formed, and while the lowest value of longitudinal modulus of elasticity was obtained at the density of $550 \mathrm{~kg} \cdot \mathrm{m}^{-3}$, the highest value of longitudinal modulus of elasticity was obtained at the density of $590 \mathrm{~kg} \cdot \mathrm{m}^{-3}$.

When Table 7 was examined; there were glues, starting from the lowest value, having $0 \%, 2,5 \%$ and $15 \%$ of melamine in the first group, and there were glues having melamine ratios of $5 \%$ and $20 \%$ in the second group, and the highest value was obtained with the glue reinforced with $20 \%$ of melamine. 
According to both density and melamine addition, the results were higher than the values of horizontal modulus of elasticity but the similar correlation was seen.

\section{Perpendicular Tensile strength to the Surface}

Changes in the values of perpendicular tensile strength to the surface obtained in the panels produced in different densities according to different (M \%) content were given in Figure 5.

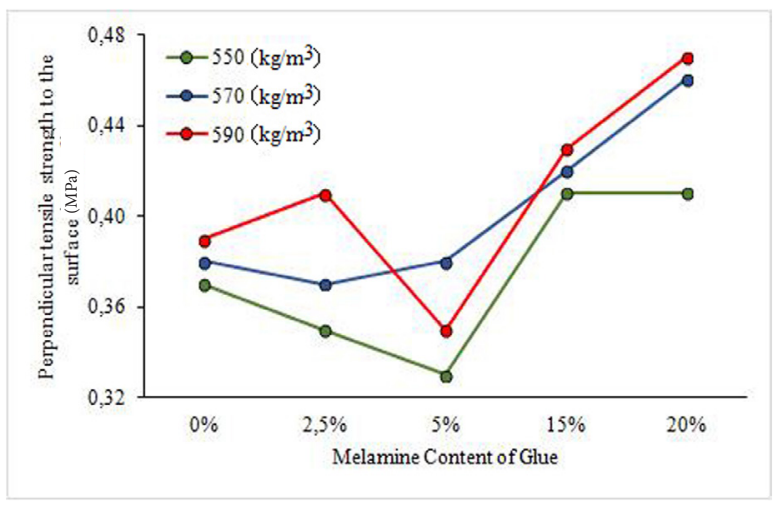

Figure 5. Change in perpendicular tensile strength to the surface according to different density and melamine content.

According to statistical results, the values of perpendicular tensile strength to the surface showed significant differences according to panel densities and melamine ratios in the glue $(p<0,05)$. The results of Duncan Test made in order to determine the effects of panel density and melamine addition percentages were given in Table 8 .

Table 8. The results of Duncan test on density and melamine content for the value of perpendicular tensile strength to the surface.

\begin{tabular}{|c|c|c|c|c|c|}
\hline \multirow{2}{*}{$\begin{array}{c}\text { Density } \\
\left(\mathrm{kg} . \mathrm{m}^{-3}\right)\end{array}$} & $\begin{array}{c}\text { Perpendicular Tensile strength to the surface } \\
(\mathrm{MPa})\end{array}$ & \multicolumn{4}{|c|}{ Homogenous Groups } \\
\hline & 0,38 & 1 & 2 & 3 & 4 \\
\hline 550 & 0,40 & $*$ & & & \\
\hline 570 & 0,41 & & $*$ & & \\
\hline 590 & & & $*$ & & \\
\hline $\begin{array}{c}\text { Melamine Ratio } \\
(\%)\end{array}$ & 0,35 & & & & \\
\hline 5 & 0,37 & $*$ & & & \\
\hline 2,5 & 0,38 & $*$ & $*$ & & \\
\hline 0 & 0,42 & & $*$ & & \\
\hline 15 & 0,45 & & & $*$ & \\
\hline 20 & & & & & $*$ \\
\hline
\end{tabular}

According to the results of Duncan test on panel density (Table 8), two homogenous groups were formed, and while the lowest value of perpendicular tensile strength to the surface was obtained at the density of $550 \mathrm{~kg} . \mathrm{m}^{-3}$, the highest values of perpendicular tensile strength to the surface were obtained in the densities of $570 \mathrm{k} \mathrm{gm}^{-3}(0,40 \mathrm{MPa})$ and $590 \mathrm{~kg} \cdot \mathrm{m}^{-3}(0,41 \mathrm{MPa})$. As well as in bending resistance and modulus of elasticity, tensile strength increased together with the density.

According to the results of Duncan Test on melamine ratios in the glue, it was seen that four homogenous groups were formed. While the lowest value of perpendicular tensile strength to the surface was given by the glues having melamine ratios of $2,5 \%$ and $5 \%$ which took place in the same group, the 
highest value of perpendicular tensile strength to the surface was given by the glue having melamine ratio of $20 \%$. The increase of reinforcement ratio increased tensile strength (especially $15 \%$ and 20\%).

\section{Thickness Swelling}

Change in the effect of different (M \%) of melamine content in the panel produced at different densities on the value of thickness swelling was given in Figure 6.

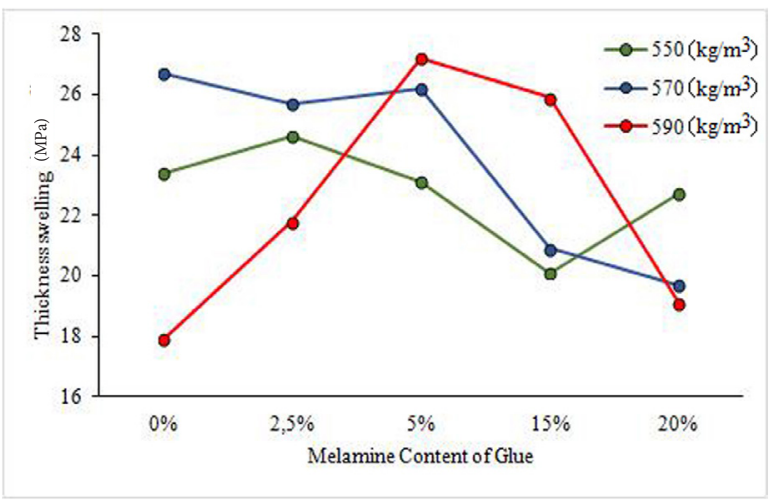

Figure 6. Change in the value of thickness swelling according to different density and melamine content.

According to statistical results, Pursuant thereto the values of thickness swelling showed significant differences according to panel densities and melamine ratios in the glue $(\mathrm{p}<0,05)$.

The results of Duncan Test made in order to determine the effects of panel density and melamine addition percentages were given in Table 9 .

Table 9. The results of Duncan test on density and melamine content for the value of thickness swelling.

\begin{tabular}{|c|c|c|c|c|c|}
\hline \multirow{2}{*}{$\begin{array}{c}\text { Density } \\
\left(\mathrm{kg} \cdot \mathrm{m}^{-3}\right)\end{array}$} & Value of Thickness Swelling & \multicolumn{4}{|c|}{ Homogeneous Groups } \\
\hline & $(\%)$ & 1 & 2 & 3 & 4 \\
\hline 590 & 22,4 & $*$ & & & \\
\hline 550 & 22,8 & $*$ & $*$ & & \\
\hline 570 & 23,9 & & $*$ & & \\
\hline Melamine Ratio & 20,5 & & & & \\
\hline 20 & 22,3 & $*$ & & & \\
\hline 15 & 22,7 & & $*$ & & \\
\hline 0 & 24,1 & & $*$ & $*$ & \\
\hline 2,5 & 25,6 & & & $*$ & $*$ \\
\hline 5 & & & & & $*$ \\
\hline
\end{tabular}

According to the results of Duncan test on panel density (Table 9) two homogenous groups were formed, and while the lowest value of thickness swelling was obtained at the density of $590 \mathrm{~kg} \cdot \mathrm{m}^{-3}$, the highest value of thickness swelling was obtained at the density of $570 \mathrm{~kg} \cdot \mathrm{m}^{-3}$.

When Table 9 was examined; it was seen that four homogenous groups were formed according to the results of Duncan test on melamine ratios in the glue. While the lowest value of thickness swelling was obtained with the glue having $20 \%$ of melamine content, the highest value of thickness swelling 
was obtained in the glue reinforced with 5\% of melamine but it took place with the glue reinforced with $2.5 \%$ of melamine in the same group. Melamine reinforcement ratio improved the value of thickness swelling.

\section{Value of Panel Free Formaldehyde}

Average results of the value of panel free formaldehyde obtained for different density and different glues were given in Table 10.



\begin{tabular}{|c|c|c|c|}
\hline \multirow{2}{*}{ Glue Type } & \multicolumn{3}{|c|}{ Panel density kg.m ${ }^{-3}$} \\
\cline { 2 - 4 } & 550 & 570 & 590 \\
\hline UF (M: 0\%) & 9,2 & 11,3 & 8,1 \\
\hline MUF (M: 2,5\%) & 6,1 & 7,2 & 5,8 \\
\hline MUF (M: 5,0\%) & 8,0 & 9,5 & 7,3 \\
\hline MUF (M: $15 \%$ ) & 6,9 & 7,0 & 6,2 \\
\hline MUF (M: $20 \%$ ) & 4,3 & 5,4 & 4,0 \\
\hline
\end{tabular}

According to OSB-definitions, classification and specifications TS EN 300 standard, while higher

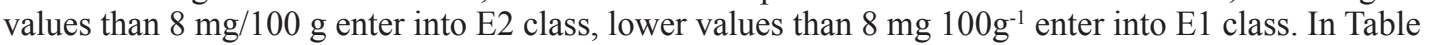
10 , as can be seen from the values of free formaldehyde obtained in melamine urea formaldehyde glue having melamine reinforcement ratio of $15 \%$ and $20 \%$, panels produced with these glues enter into E1 class. It can be seen in Table 10 that as melamine content increases, panel free formaldehyde value decreases.

\section{CONCLUSIONS}

Within the scope of the study, obtained results show that there is a linear correlation between the value of horizontal bending resistance, modulus of elasticity with panel density and melamine amount. It was understood that the values of longitudinal bending resistance did not show a direct increasing or decreasing in melamine amount and value of density. As far as we are concerned this is directly correlated with chip sizes especially chip length and directing shapes in laying unit of chips used in lower and upper surfaces of the panel. As it is seen that the values of longitudinal modulus of elasticity increases in proportion with the increase in the density (except two values), there is not a significant and regular effect of melamine reinforcement. In perpendicular tensile strength to the surface; it is seen that values of all glue groups and density values which are intended by the standard for density values are covered; and as melamine reinforcement ratio increases, perpendicular tensile strength to the surface also increases. As melamine reinforcement ratio increases, average values of free formaldehyde decrease. As melamine ratio in urea formaldehyde glue increases, statistically, there is no significant difference in the values of strength. It was determined that there was no direct correlation between the value of thickness swelling and panel density, and it had a correlation with used glue type.

Consequently, it was determined with this study that panels can be formed according to their places of use with melamine reinforced glues which are easier to supply and process at low panel densities than other glues. Also, it was revealed that as panel density increases, there is an increase in every strength values except the value of thickness swelling, and the value of thickness swelling is affected directly by variations of glues, not panel density. It was projected that factors affect mostly the value of thickness swelling were amount and quality of hydrophobic chemical used (generally paraffin emulsion), type, quality and amount of glue used. Because consumption amount of wood will be lesser at lower panel density, resources will be used more productively as well contribution to the economy will be provided by reducing panel manufacturing costs. 


\section{REFERENCES}

Akbulut, A. 1999. The effect of various manufacturing variables on technological properties of particleboards. Ph.D. Thesis, İstanbul University, Institute Graduate Studies in Science and Engineering, İstanbul.

Akbulut, T.; Goker, Y.; Ayrilmis, N. 2002. Using OSB panels instead of plywood. Journal of the Faculty of Forestry Istanbul University 52(1): 65-80.

Avramidis, S.; Smith, L.A. 1989. The effect of resin content and face-to-core ratio on some properties of oriented strand board. Holzforschung 43(2): 131-133.

Böhm, M.; Šedivka, P.; Bomba, J.; Reisner, J. 2011. Strength characteristics of OSB in bending - difference between upper and lower panel faces. Drvna Industrija 62 (2): 123-127.

Barbuta, C.; Blanchet, P.; Cloutier, A. 2012. Mechanical properties of unidirectional strand board (USB) with flat vertical density profile. Journal of Materials Science Research 1(3): 42-49.

Bozkurt, Y.; Goker, Y. 1990. Particleboard Industry. İstanbul: İstanbul University Faculty of Forestry.

Brochmann, J.; Edwardson, C.; Shmulsky, R. 2004. Influence of resin type and flake thickness on properties. Forest Product Journal 54(3): 51-55.

Bufalino, l.; Correa, A.A.R.; De Sa, V.A.; Mendes, L.M.; Almeida, N.A.; Pizzol, V.D. 2015. Alternative compositions of oriented strand boards (OSB) made with commercial woods produced in Brazil. Maderas-Cienc Tecnol 17(1): 105 - 116.

Candan, Z.; Shaler, M.S.; Heller, J.J.P.; Edgar, R. 2017. Enhancing dimensional stability of oriented strand Composites within biorefinery. Maderas-Cienc Tecnol 19(3): 387-398.

Esen, R.; Yapıcı, F.; Yörür, H. 2013. The effect of press time and press pressure on the screw strength properties of oriented strand board (OSB) manufactured from Scots pine. ProLigno 9(4): 456459.

Febrianto, F.; Hidayat, W.; Samosir, T.P.; Lin, H.C.; Soong, H.P. 2010. Effect of strand combination on dimensional stability and mechanical properties of oriented strand board made from tropical fast growing tree species. Journal of Biological Science 10(3): 267-272.

Goker, Y.; Akbulut, T. 1992. Factors affecting the properties of particleboard and plywood. Orenko'92: I. National Forest Industry Product Symposium, Trabzon.

Gunduz, G.; Yapıcı, F.; Ozçiftci, A.; Kalaycioglu, H. 2011. The Effects of adhesive ratio on pressure time on some properties of oriented strand board. Bioresources 6(2): 2118-2124.

Irle, M.; Barbu, MC. 2010. Wood based panels: an introduction for specialists. ed Heiko Thoeman; GB Inggris; Mark Irle; Milan Sernek. London: Brunel University Press

Jaroslav, H.; Pavel, K. 2009. Determination of relationships between density, amount of glue and mechanical properties of OSB. Drvna Industrija 60(1): 7-14.

Mendes, R.F.; Junior, G.B.; de Almeida, N.F.; Surdi, P.G.; Barbeiro, I.N. 2013. Effects of thermal pre-treatment and variables of production on properties of OSB panels of Pinus taeda. MaderasCienc Tecnol 15(2): 141-152.

Nemli, G. 2002. Factors affecting the production of $\mathrm{E}_{1}$ type particleboard. Turkish Journal of Agriculture and Forestry 26(1): 31-36. 
Nemli, G. 2003. Effects of some manufacturing factors on the properties of particleboard manufactured from adler. Turkish Journal of Agriculture and Forestry 27(2): 99-104.

Suziki, S.; Takeda, K. 1999. Production and properties of japanese oriented strand board I: effect of strand length and orientation on strength properties of sugi oriented strand board. Journal of Wood Science 46(4): 289-295.

Saldanha, L.; Iwakiri, S. 2009. Effects of density and kind of resin in the properties of OSB of Pinus taeda L. Journal Floresta 39(3): 571-576.

Turkish Standards Institution. 1999a. Wood- Based panels- Determination of density. TS EN 323, Ankara.

Turkish Standards Institution. 1999b. Wood- Based panels- Determination of modulus of elasticity in bending and of bending strength. TS EN 310, Ankara.

Turkish Standards Institution. 1999c. Particleboards and fibreboards- Determination of tensile strength perpendicular to the plane of the board. TS EN 319, Ankara.

Turkish Standards Institution. 1999d. Particleboards and fibreboards- Determination of swelling in thickness after immersion in water. TS EN 317, Ankara.

Turkish Standards Institution. 1999e. Wood-based panels- Determination of moisture content. TS EN 322, Ankara.

Turkish Standards Institution. 1999f. Particleboards- Determination of moisture resistance- Part 1: Boil test. TS EN 1087-1, Ankara.

Turkish Standards Institution. 1999g. Wood based panels- Determination of formaldehyde content- Extraction method called the perforator method. TS 4894 EN 120, Ankara.

Turkish Standards Institution. 2008. Oriented strand boards (OSB)-Definitions, classification and specifications. TS EN 300, Ankara.

Young, B. N.; Kim, M. G. 2007. Evaluation of melamine modified urea formaldehyde resin as particleboard binders. Journal of Applied Polimer Sience 106(6): 4148-4156.

Zhou, A. 1990. A study oriented structural board made from hybrid poplar. Holz als Roh-und Werkstoff 48:293-296. 